\title{
Podcasting: Spaces for Connection and Development
}

\section{Matthew W. Turner \\ Toyo University}

\section{Reference Data:}

Turner, M. W. (2020). Podcasting: Spaces for connection and development. In P. Clements, A. Krause, \& R. Gentry (Eds.), Teacher efficacy, learner agency. Tokyo: JALT. https://doi.org/10.37546/JALTPCP2019-05

ELT could be viewed as a community of practice, with various professionals engaging in processes of collective learning in a shared domain of interest. Yet accessible, mutual, and dialogic communication across ELT's sub-disciplines is often curtailed. As there are things to learn from the work of others, from pedagogical activities and beliefs to empirical findings, new spaces for purposeful and actual dialogue may need to be explored. In this paper I propose podcasts as such a platform in which practitioners can cooperatively and publicly develop understandings through interaction. The paper opens with an overview of how podcasts are used as tools for education and professional development, followed by a look into the nature and importance of dialogic reflection in teacher learning. By offering transcript data from an episode of the author's ongoing podcasting project, I provide an investigation of how podcast interviews can facilitate the participants' collaborative co-construction of mutual understanding.

ELTの様々な二次的な專門分野にアクセスしやすく、互いに共有できる対話によるコミユニケーションの場は、しばしば二の 次となっているのが現状である。しい、教授法や信念、そして央証的所見にいたるまで、他から学べることは多々ある。そのた

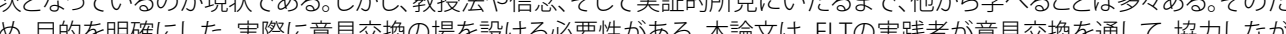
め、目的を明確にした、実際に意見交換の場を設りる必要性がる。本論文は、ELT実践者が意見交換を通して、協力しなが

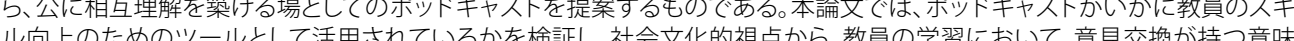

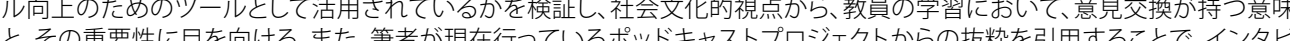
と、その重要性に目を向ける。また、筆者が現在行っているポッドキャストプロジェクトからの抜粋を引用することで、インタビ odcasts have emerged as a participatory media platform through which different groups of professionals can interact with one another. However, within the shared endeavour of English language teaching (ELT), and more broadly applied linguistics, fractured cooperation between different theory and practice-based members is a prevalent issue (Rose, 2019). This divide is exacerbated by the assumption of a hierarchical arrangement between the "ivory tower" academics and those plying away at the chalkface of language teaching (Prabhu, 1990). The reasons for the difficulties in engagement across the field are often systemic because language teachers might lack the impetus or institutional incentives to participate in academic or continuing professional development (CPD) activities (Nassaji, 2012). On another level, the relevance of research and empirical studies might not be suitably transmitted and made salient to all groups (Borg, 2009). Although teacher research has gained considerable credence, the community might need to find and establish more innovative and accessible interface tools that further foster open, purposeful, and actual exchanges among different subdisciplines.

Engaging with dialogues might help those from different sub-disciplines to learn from one another more effectively. Zeldin (1998) defined dialogues broadly as meetings of minds with different memories and habits, creating spaces where facts are not just exchanged, but transformed and reshaped, with implications drawn and new trains of thought engaged in. Dialogues could be considered an important mechanism that supports communities of practice-joint enterprises of members in binding mutual engagement (Wenger, 1998). Podcasts are a potential apparatus for bringing members of a professional community together in meaningful dialogue. To look at this, extracts from an interview conducted between Diane Larsen-Freeman and a creator of an ongoing podcasting project (see Appendix) are presented, illustrating instances of individuals from different sub-disciplines in constructive and reflective dialogue. The extracts will be examined to identify some of the different interactive features that show how podcast exchanges provide a co-constructive and supportive space for the explorative sharing of 
issues related to the field. To see how collaborative understanding develops, Edge's (2002) cooperative development (CD) discourse framework is applied, focusing on the aspects of reflection, challenge, and focus in the dialogue. Although more thorough investigations into the dynamics of podcasting in the field are needed, it is hoped that this anecdotal glimpse shows the potential function that podcasts might play in connecting different groups across a shared community through meaningful dialogue.

\section{Using Podcasts}

Over the last decade, podcasting has grown steadily in terms of the amount of shows produced, the range of innovative formats created, and listener figures. Podcasts are a familiar technology across areas such as media, the arts, and education, as well as an established instructional and material resource for language learning (Rosell-Aguilar, 2007). Podcasts are also considered a disruptive technology, in their challenge to traditional media forms (Fox \& Llinares, 2018), and revolutionary, in their founding of alternative aural cultures and genres (Spinelli \& Dann, 2019). One type of culture that podcasts have promoted is an engagement in subject areas that previously might have been less openly accessible. Podcasts are acknowledged as having "intimate bridging qualities" (Swiatek, 2018, p.175), given the way that they help to facilitate and present comprehensible interdisciplinary interaction between different communities of inquiry and interest. In addition, Birch and Weitkamp (2010) used the term podologue to describe how the medium is used to popularise, informalize, and stimulate wider interest in the sciences. Through podcasts, therefore, audiences have the chance to listen to, engage with, and learn from members of different professional and academic backgrounds performing and participating in accessible dialogue.

Different educational programmes have experimented with podcasts. For example, studies by Güler and Özkan (2018), and Strickland, Gray, and Hill (2012) observed how the introduction of podcasts to preservice teacher and nurse training programmes allowed for engaging ways to facilitate links between research and practice, with participants indicating increased content comprehension and interest through using the technology. Other studies examined how the team production of podcasts functioned as catalysts for collaborative knowledge building amongst groups of students (Killean \& Summerville, 2020; Lee, McLoughlin \& Chan, 2008). An increased sense of agency brought about by developing tangible products, led to supportive teamwork atmospheres, and chances for creative problem-solving and skill development chances. In the geography field, Kinkaid Emard, and Senanayake (2020) reflected on a podcast-as-method approach to research activities, by discussing how podcasts provide a format for the multi-voiced production of geographic knowledge. The authors experimented with collaborative podcast production for data collection and research analysis and distribution, noting that the approach has the potential for heightened public engagement, due to the visceral qualities of the aural medium. Aside from their utilisation within educational settings, there is also a growing interest in podcasts as part of a collection of independent CPD initiatives of practicing teachers (Woodford \& Southcott, 2018), in that they generate opportunities for participating in and listening to peer dialogue.

\section{Dialogic Reflection}

Reflective practice (RP) refers to activities, both intellectual and practical, that are disposed to processes of structuring and restructuring professional beliefs, knowledge, theories, and actions (Zwozdiak-Myers, 2012). RP is considered important in developing teachers' self-efficacy and has gained a central role in language teacher education (e.g., Farrell, 2016; Mann \& Walsh, 2013; Wyatt, 2016). Research has shown that dialogic forms of reflection offer rich options for professional learning and development (Chick, 2015). Dialogic reflection is supported by a sociocultural perspective that views learning as being mediated by language and other symbolic artefacts, with development taking place through the social activity that is being engaged in (Johnson \& Golombek, 2003). The ability to communicate in cooperative, non-judgemental, and supportive interfaces cultivates a mediational space that is conducive to the occurrence of growth and understanding. Although learning is supported through informal talk with peers, structured protocols for reflection assist teachers to achieve the clear articulation and actioning of ideas (Blake \& Gibson, 2020). Yet, some researchers have suggested that more data-led accounts of practitioners' dialogic reflections are needed in order to establish how these activities are really carried out (Walsh \& Mann, 2015). The term "in the wild" (Mann \& Walsh, 2017) has also been proposed as a way to locate and identify ELT practitioners' reflective inquiry activities that are "integrated and embedded in daily professional lives" (p. 100) where they are working independently in contexts outside formal educational settings. Podcast production initiates opportunities for dialogic reflection, as an independent professional development activity, which potentially triggers further learning and engagement, as well as ensuring a repository of usable examples of such reflective activities.

Podcasting for Professional Engagement and Learning In 2014, The TEFLology Podcast was launched. The show is released fortnightly and consists of a variety of formats including discussions on theoretical, pedagogical, and historical 
topics, interviews with scholars in the field, and audio productions of text-based resources, such as book chapters. The chances to develop interpersonal relationships within a community, the option to enhance different skills, and the space to interact about subject matters of interest were identified as the motives of independent producers to start and continue a podcast (Markham, 2012). Similarly, The TEFLology Podcast creators describe their project as a "reflective enterprise," in relation to the ways that the podcast has helped the group to keep up a keen engagement with different issues and topics in the profession. For example, the project helped the podcasters to form and establish a "critical copresenter" relationship, defined as the public record of collaborative talk that aids critical discussion and reflection with the aim of developing one's own and others' professional awareness (Lowe, Schaefer, \& Turner, 2017). As such, through the routine preparation and discussion of topics related to the profession, podcasts have been suggested as an option for practitioners to reflectively engage with research (Turner, Lowe, \& Schaefer, 2020). The show is helping to transform the way conventional procedures of transmitting ideas are approached, enabling experimentation with more communicative and collaborative forms of knowledge production, delivery, and sharing. For example, a previous JALT forum session was used to bring together a diverse group of invited conference speakers to establish connections between each other's areas of interest through an assortment of interview and panel discussion exchanges (Turner et al., 2019). The aim was to create chances for panellists to uncover emergent commonalities between their different specialities as well as opportunities for the podcast producers to build up their critical understandings of participants' research activities and ideas.

This paper focuses in particular on the use of interviews on The TEFLology Podcast. The interviews function as a structured model of dialogic reflection for the producers as an independent CPD activity and as a resource for ELT practitioners. The exchanges typically involve a process by which interviewers consider and explore interviewees' scholarly activities, with an emphasis on developing collaborative understanding while remaining mindful of the public nature of the exchanges, as well as the podcasting genre. As such, the areas of RP and podcasting merge, generating an alternative resource for the ELT community. With regard to podcasts for educational purposes, Drew (2017) identified the chat show as being a commonly used genre, defined as the "utilisation of institutionalised conversation between two or more participants to explore various ideas and concepts" (p. 207) that support learning by putting metalanguage into a conversational context modelled around the form and function of everyday language situations. In addition, the blending of humour, informality, and intellectualism helps to create an immersive cognitive tool for audiences. The TEFLology Podcast's interviews largely follow and reflect what is considered to be the chat show genre.

\section{Conceptual Framework}

A sociocultural perspective places emphasis on the way that developmental movements happen through the collaborative spaces afforded by dialogue. Interview dialogues involve a process of co-construction, whereby interaction and meaning gets negotiated jointly between participants, with the interviewer being pivotal in the shaping and understanding of interviewee responses (Rapley, 2001). In returning to RP, Edge's (2002) cooperative development $(\mathrm{CD})$ model resonates with the notion of co-construction. $\mathrm{CD}$ is defined as a deliberate approach of communicating with others to carefully work on individual self-development (p. 18). Like interviews, CD interactions are guided by certain conventions, with "speaker" (interviewee) and "understander" (interviewer) roles observed for a set amount of time in order to ensure for an explorative space. Unlike CD however, interviews may not always take place for the conscious purpose of development. This being said, interviewers, whilst questioning and remaining attentive to what interviewees are talking about, arguably undergo a process of growth by learning from interviewees' words and reinforcing new insights through follow-up responses. By being questioned, interviewers may articulate information about their beliefs in different ways, and also reach new understandings. As a discourse framework for selfdevelopment, $\mathrm{CD}$ includes terms such as reflecting, challenging, and focusing, which are used to plot these movements. Although this interview is not an example of $\mathrm{CD}$, these aspects are borrowed to guide the analysis.

Extracts from the transcript of the interview have been simplified out of consideration for the focus of this paper, with various interactive features of the exchange omitted to provide a cleaner representation. For greater transparency and accuracy, a link to the full audio interview is provided in the Appendix. The aim of this paper is to show how podcast interviews can be used as reflective activities and resources for the ELT community. To address this, a micro-analytical approach is taken that explores the language features of interaction and how the process of co-construction is undertaken by participants (Mann, 2016)

\section{Analysis}

The interview with Diane Larsen-Freeman was conducted at the JALT2018 conference. Diane is considered a leading figure in applied linguistics known for her work on complexity theory (see Larsen-Freeman, 2013). The rationale for interviewing Diane was to gain an understanding of complex dynamic systems theory (CDST) and explore how these ideas can be applied to practical language learning settings. Consent was given for the interview to be shared as a public audio resource and for use in this paper. The 
following subsections will shift in style and be written from the perspective of the author, in order to capture some autoethnographical interpretations of his personal participation as the interviewer.

\section{Reflecting}

Reflecting requires the interviewer to mirror the interviewee's thoughts, in order to encourage progress, facilitate insight, and ascertain what is being said. It also helps participants to reach common ground with each other, as well as establish clarity and focus (Edge, 2002). A role of interviewers is to ensure that any detailing of concepts is made salient and comprehensible to themselves, and by extension to listeners. The following extract shows my attempt to reflect on what Diane is saying in order to check and further facilitate my understanding:

\begin{tabular}{|c|c|c|}
\hline 01 & D: & Complex and the way the theory talks has to do with the \\
\hline 02 & & interaction of the components giving rise to new patterns at \\
\hline 03 & & another level of complexity, (M: Yeah) if that makes any \\
\hline 04 & & sense? \\
\hline 05 & M: & I understand, yeah. I think I saw you write somewhere you \\
\hline 06 & & talked about a flock of birds... \\
\hline 07 & D: & Well that's not my example (M: Okay) but I use it often \\
\hline 08 & & because it makes a lot of sense... \\
\hline 09 & M: & Yeah that was the one that really struck a chord, yeah... \\
\hline 10 & D: & ...to people. You have birds, you know, pecking on the \\
\hline 11 & & ground, you walk by and they take off, there's no one lead \\
\hline 12 & & bird. They just take off as one, (M: Umm) they become a \\
\hline 13 & & kind of superorganism. And so, at another level of \\
\hline 14 & & granularity you get a different level of complexity. \\
\hline 15 & M: & Yeah \\
\hline
\end{tabular}

The extract opens with Diane qualifying what she means when describing what her conception of complexity refers to. Diane attempts to confirm if I am understanding and following her explanation by asking "if that makes any sense?" in lines 3 and 4. Upon confirming that I understand what is being said, Diane's use of the words "new patterns" on line 2 triggers me to recall an analogy that she uses in her writings. Diane describes complexity with a bird analogy, which although not originally her own, she considers making "a lot of sense." This encourages me to inform her of its usefulness for me personally ("Yeah that was the one that really struck a chord, yeah..."). Here, the shift in focus to thinking about this analogy leads Diane to briefly describe its significance and how it helps to characterise and portray complexity theory. In her explanation, Diane uses what are arguably quite specific words such as "superorganism" in line 13 and "granularity" in line 14, which may detract from some of the overall clarity. However, these terms also lend themselves to the example that the exchange develops a focus on, and they help me to visualize, ground, and bring to life the theoretical concept. Throughout the extract, and indeed throughout the rest of the interview, my verbal backchanneling responses of "yeah," "okay," and "umm" show Diane that I am following and considering her words, and on this occasion, I am able to facilitate an additional articulation of her ideas.

Podcasts can offer spaces in which ideas can be clarified and confirmed. This extract shows the $\mathrm{CD}$ feature of reflecting in use, whereby a piece of information, in this case an external reference, is focused on as a way of further ascertaining and making sense of some of the themes being discussed.

\section{Challenging}

Challenging are moves used to reconcile and bring together different statements made by interviewees to establish a clearer position (Edge, 2002). Podcasts offer interviewers with an opportunity to discuss their thoughts about a researcher's area of expertise directly with them, affording a space for critical dialogue. In this extract, I identify a point of tension between the rigidness of language assessment measurements and the theorising and describing of language systems as being fluid, complex, and dynamic. With the view that these positions may not seem to align neatly, I invite Diane to attend to this issue: 


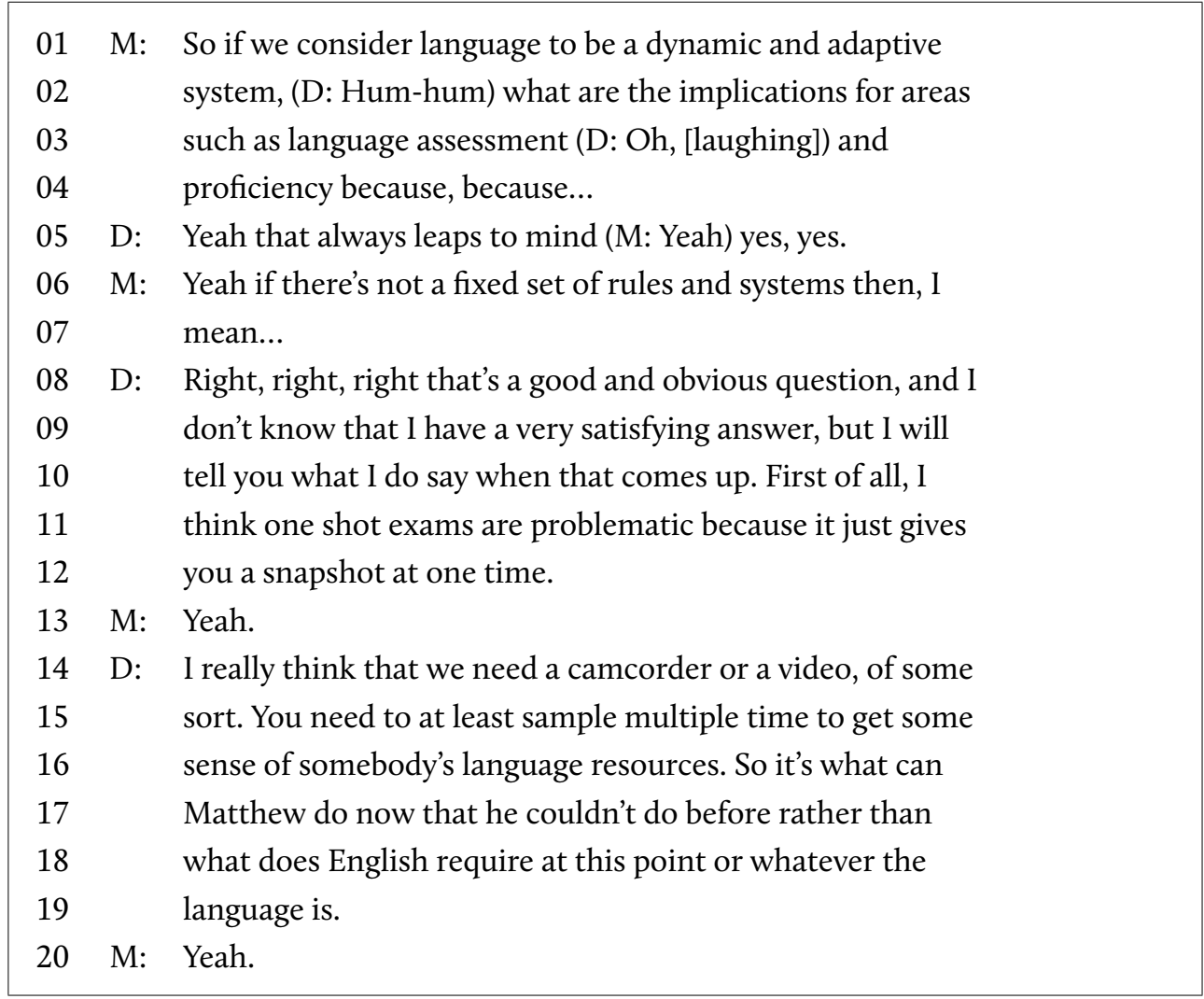

I appear to be nervous and cautious when delivering my question. For example, in lines 1 to 4 , Diane is offered a number of chances to react before the question is formulated. This could highlight a sense of risk on my part as well as show an appreciation of how difficult answering this question might be. In line 3 , Diane's response of laughter denotes some acknowledgement and agreement with the difficult aspect of the point that I am looking to explore. Indeed, Diane's next utterance in line 5 of "yeah that always leaps to mind" shows that this is a contentious and prevailing issue within Diane's area of research, and one that is likely to have arisen and been considered before. In response to her reaction to the opening part of my question, I make an attempt to justify and support my line of inquiry ("yeah if there's not a fixed set of rules and systems then, I mean"). Here, my display of personal feelings and awareness of the point being raised could be seen as an attempt to lighten the delivery of a potentially problematic question. In line 8, Diane shows that she is welcoming of the point ("that's a good and obvious question"), following up by admitting in an honest way that she doesn't have a "satisfying answer." Diane goes on to give a personal response to the question, with line 14 suggesting some emotive orientations to the topic ("I really think that we need a camcorder or a video").

This extract shows the feature of challenging, where different statements made by the interviewee are reconciled to establish an enhanced position of understanding. Interviewees can viscerally and authentically readdress their thoughts on poignant subject matter in their field. Although for Diane it is likely that she could be returning to topics that have been addressed before, for me, the process of identifying and reaching this point, delivering a question, and then considering upon Diane's response, offers the chance for some self-development and a deeper understanding of the point in focus.

\section{Focusing}

Focusing involves guiding talk towards a specific purpose. Edge (2002) states that a level of specificity must be achieved in exploratory dialogue to lead towards discoveries as bases for action (p. 97). One specific purpose of this encounter was to develop a personal understanding of how CDST could be applied to the practice of language teaching. In the interview, there is a shift towards bringing together CDST and classroom practice: 
01 M: And how, I mean, in a practical sense, how could that be realised?

D: One of the issues of complexity theory is I think it's so terribly profound, it's really altered the way I think in a radical way. But then there's also part of me that says it's very banal because don't teachers do this already in some ways? (M: Yeah, yeah) And it resonates with teachers because I think it is sort of commonsensical. So, how do teachers do that? I think that, I mean, this is probably not very realistic, but how about abandoning the syllabus and, this is not realistic? And, just letting the students,

whatever kind of language resources, even rank beginners, no one's totally a beginner (M: Umm yeah) of English these days. And, start to use what they have, and use that, I call it an organic syllabus, use that as a way to move forward (M: Yeah) so you're relating to what the students bring with them and moving on from that, as opposed to coming with a preordained or (M: I see, yeah) configurated syllabus...

M: So you're kind of uncovering (D: Yeah) rather than covering, I guess (D: Yeah yeah yeah) that's it.

In lines 1 and 2, an attempt is made to move the focus of the dialogue to practical issues. My use of "I mean" allowed for time to ensure that my question could be delivered correctly, affording me to the chance to use the appropriate terminology. After Diane's initial reflection, in which she appears to display a sense of friction with terms such as "radical," "banal," and "commonsensical," she returns to the point in focus in lines 8 and 9 by saying "so, how do teachers do that?" This could also be seen as a way of allowing herself thinking time, before continuing with her response. Diane cushions her idea of "abandoning the syllabus" in line 10 by acknowledging twice that it may not be "realistic" in lines 10 and 11. She qualifies and reinforces her idea by saying "I call it an organic syllabus," giving the impression that this is again something that she has likely discussed before, which also acts to support and formalize the earlier "unrealistic" opening. Later in the extract, I interject by saying "so you're kind of uncovering rather than covering," which could be an example that shows how I am beginning to internalize and make sense of the practical implications of Diane's consideration of my initial question.

This extract shows the aspect of focusing in operation whereby a shift from theoretical research ideas to an emphasis on other applications, such as classroom practice, takes place to guide the talk towards a specific outcome. Podcasts can offer producers and listeners the chance to establish sub-disciplinary connections and make steps towards acting on and applying what is being learnt.

\section{Concluding Reflections}

This paper has explored how podcasts can be used as an apparatus for creating meaningful spaces for collaborative and co-constructive dialogue between different sub-disciplinary members of the ELT community. For the podcast's participants, they allow for themes to be attended to dialogically and critically, movements towards purposeful self-development to be set in motion, and reflection to ensure a greater clarity in understanding ideas. Whilst further research is needed to assess the nature and effectiveness of the podcast as an interfacing tool in ELT, podcasting has the potential to be a beneficial CPD initiative that helps to uphold and develop practitioners' sense of efficacy, connection, and commitment with the profession. In addition, through podcast interviews, interviewees not only have the chance to share and discuss their work in a more accessible and informal tone, they are also potentially afforded the opportunity to rethink and recast their own output and beliefs. For listeners also, who are essential to the success and continuation of podcasting projects, audio recordings of interviews may also operate as a valuable learning resource, exposing them to more open, intimate, and comprehensible contact with individuals who have interesting and worthwhile ideas to share. This paper has hopefully provided an anecdotal snapshot of the dynamic roles that podcast participation and production may have for practitioners in the ELT community.

\section{Bio Data}

Matthew W. Turner is an English language lecturer at Toyo University. He holds an MA in applied linguistics and TESOL from the University of Leicester and is currently working towards a PhD at the University of Warwick. His different research interests include reflective practice, podcasting in language teacher education, accessible tourism, 
and support for learners with special educational needs. Matthew is co-creator of The TEFLology Podcast and current coordinator of JALT's Teacher Development SIG. <turner@toyo.jp>

\section{References}

Birch, H., \& Weitkamp, E. (2010). Podologues: Conversations created by science podcasts. New Media \& Society, 12(6), 889-909. https://doi.org/10.1177/1461444809356333

Blake, J., \& Gibson, A. (2020). Critical friends group protocols deepen conversations in collaborative action research projects. Educational Action Research, 1-16.

https://doi.org/10.1080/09650792.2020.1717568

Borg, S. (2009). English language teachers' conceptions of research. Applied Linguistics, 30(3), 358388. https://doi.org/10.1093/applin/amp007

Chick, M. (2015). The education of language teachers: instruction or conversation? ELT Journal, 69(3), 297-307. https://doi.org/10.1093/elt/ccv011

Drew, C. (2017). Educational podcasts: A genre analysis. E-learning and Digital Media, 14(4), 201 211. http://dx.doi.org/10.1177/2042753017736177

Edge, J. (2002). Continuing cooperative development: A discourse framework for individuals as colleagues. Ann Arbor, MI: University of Michigan Press.

Farrell, T. S. C. (2016). Anniversary article: The practices of encouraging TESOL teachers to engage in reflective practice: An appraisal of recent research contributions. Language Teaching Research, 20(2), 223-247. https://doi.org/10.1177/1362168815617335

Fox, N., \& Llinares, D. (2018). Cinematologists: Knowing sounds. Media Practice and Education, 19(1), 48-51. https://doi.org/10.1080/14682753.2017.1362170

Güler, S., \& Özkan, Y. (2018). Podcast applications in pre-service language teacher education from a constructivist perspective. World Journal on Educational Technology: Current Issues, 10(3), 131141. https://doi.org/10.18844/wjet.v10i3.3552

Johnson, K., \& Golombek, P. (2003). “Seeing” teacher learning. TESOL Quarterly, 37(4), 729-737. https://doi.org/10.2307/3588221

Killean, R., \& Summerville, R. (2020). Creative podcasting as a tool for legal knowledge and skills development. The Law Teacher, 54(1), 31-42. https://doi.org/10.1080/03069400.2019.1568675

Kinkaid, E., Emard, K., \& Senanayake, N. (2020). The podcast-as-method?: Critical reflections on using podcasts to produce geographic knowledge. Geographical Review, 110(1-2), 78-91. https://doi.org/10.1111/gere.12354

Larsen-Freeman, D. (2013). Complexity theory. In S. M. Gass \& A. Mackey (Eds.), The Routledge handbook of second language acquisition (pp. 91-106). Abingdon: Routledge.
Lee, M., McLoughlin, C., \& Chan, A. (2008). Talk the talk: Learner-generated podcasts as catalysts for knowledge creation. British Journal of Educational Technology, 39(3), 501-521. https://doi.org/10.1111/j.1467-8535.2007.00746.x

Lowe, R. J., Schaefer, M. Y., \& Turner, M. W. (2017). Podcasting and professional development: A guide for English language teachers. The Round. Available from http://the-round.com/resource/ podcasting-and-professional-development/

Mann, S. (2016). The research interview. London: Palgrave Macmillan.

Mann, S., \& Walsh, S. (2013). RP or 'RIP': A critical perspective on reflective practice. Applied Linguistics Review, 4(2), 291-315. https://doi.org/10.1515/applirev-2013-0013.

Mann, S., \& Walsh, S. (2017). Reflective practice in English language teaching. Abingdon: Routledge.

Markman, K. M. (2012). Doing radio, making friends, and having fun: Exploring the motivations of independent audio podcasters. New Media \& Society, 14(4), 547-565.

https://doi.org/10.1177/1461444811420848

Nassaji, H. (2012). The relationship between SLA research and language pedagogy: Teachers' perspectives. Language Teaching Research, 16(3), 337-365. https://doi.org/10.1177/1362168812436903

Prabhu, N. S. (1990). There is no best method-Why? TESOL Quarterly, 24(2), 161-176. https://doi.org/10.2307/3586897

Rapley, T. (2001). The art(fulness) of open-ended interviewing: Some considerations on analysing interviews. Qualitative Research, 1(3), 303-323. https://doi.org/10.1177/146879410100100303

Rose, H. (2019), Dismantling the ivory tower in TESOL: A renewed call for teaching-informed research. TESOL Quarterly, 53(3), 895-905. https://doi.org/10.1002/tesq.517

Rosell-Aguilar, F. (2007). Top of the pods: In search of a podcasting "podagogy" for language learning. Computer Assisted Language Learning, 20(5), 471-492.

https://doi.org/10.1080/09588220701746047

Spinelli, M., \& Dann, L. (2019). Podcasting: The audio media revolution. New York: Bloomsbury.

Strickland, K., Gray, C., \& Hill, G. (2012). The use of podcasts to enhance research-teaching linkages in undergraduate nursing students. Nurse Education in Practice, 12(4), 210-214. https://doi.org/10.1016/j.nepr.2012.01.006

Swiatek, L. (2018). The podcast as an intimate bridging medium. In D. Llinares, N. Fox, \& R Berry (Eds.), Podcasting: New aural cultures and digital media (pp. 173-187). London: Palgrave Macmillan.

Turner, M. W., Schaefer, M. Y., Lowe, R. J., Alizadeh, M., Bao, D., \& O’Loughlin, J. B. (2019). Diversity through interaction: An interview forum. In P. Clements, A. Krause, \& P. Bennett (Eds.), Diversity and inclusion (pp. 243-252). Tokyo, Japan: JALT.

https://doi.org/10.37546/JALTPCP2018-08 
Turner, M. W., Lowe R. J., \& Schaefer, M. Y. (2020). Professional development and research engagement through podcasting. ELT Research, 35, 28-31. Retrieved from

http://resig.weebly.com/uploads/2/6/3/6/26368747/turneretal.eltresearch2020_resig_.pdf

Walsh, S., \& Mann, S. (2015). Doing reflective practice: A data-led way forward. ELT Journal, 69(4), 351-362. https://doi.org/10.1093/elt/ccv018

Wenger, E. (1998). Communities of practice: Learning as a social system. Systems Thinker, 9(5).

Retrieved from https://thesystemsthinker.com/communities-of-practice-learning-as-a-socialsystem/

Woodford, H., \& Southcott, J. (2018). Sparking ideas: English teacher use of online tools for professional learning. English in Australia, 53(1), 42-51. Retrieved from https://search.informit. com.au/browsePublication;py=2018;vol=53;res=lELHSS;issn=0155-2147;iss=1

Wyatt, M. (2016). "Are they becoming more reflective and/or efficacious?" A conceptual model mapping how teachers' self-efficacy beliefs might grow. Educational Review, 68(1), 114-137. https://doi.org/10.1080/00131911.2015.1058754

Zeldin, T. (1998). Conversation: How talk can change our lives. London: The Harvill Press.

Zwozdiak-Myers, P. (2012). The teacher's reflective practice handbook: Becoming an extended professional through capturing evidence-informed practice. Abingdon: Routledge.

\section{Appendix}

Diane Larsen-Freeman Interview Recording

Turner, M. W., Lowe, R. J., \& Schaefer M. Y. (Producers). (2019, August 21). TEFL Interviews 56: Diane Larsen-Freeman on Complexity [Audio podcast]. Retrieved

from http://teflology.libsyn.com/tefl-interviews-56-diane-larsen-freeman-on-complexity 